\title{
DYNAMIC CONTRACTING MECHANISM FOR PAVEMENT MAINTENANCE MANAGEMENT
}

\section{Hatice Cigdem Demirel Hennes De Ridder}

1. Faculty of Civil Engineering and Geosciences, Delft University of Technology, Stevinweg 1, 2628 CN, Delft, The Netherlands; PH +31152784774; e-mail: h.c.demirel@tudelft.nl

2. Faculty of Civil Engineering and Geosciences, Delft University of Technology, Stevinweg 1, 2628 CN, Delft, The Netherlands; PH +31152784774; e-mail: h.a.j.deridder@tudelft.nl

3. Faculty of Civil Engineering and Geosciences, Delft University of Technology, Stevinweg 1, 2628 CN, Delft, The Netherlands; PH +31152784774; e-mail: j.g.verlaan@tudelft.nl

\begin{abstract}
Technological advances, financial possibilities and changes of demands have increasingly affected the pavement maintenance environment for outsourcing in recent years. This induces complexity in the contracting methods of pavement maintenance activities. Despite the fact that current contracting practices on pavement maintenance activities are not sufficient to deal with changes providing the improved level of services. Therefore road agencies are needed to enable appropriate contracting methods to provide efficient pavement maintenance for their asset management systems. A suitable contracting mechanism can be mentioned to assist road agencies in finding optimum strategies for providing and managing pavement assets in a serviceable condition per time step. This paper aims to develop an optimal contracting mechanism to aid asset managers and contractors in making cost effective decisions and efficient outsourcing of pavement maintenance activities in asset management system for Dutch road network.
\end{abstract}

Key words: Pavement Maintenance, Contracting Mechanism, Outsourcing, Asset Management 


\section{INTRODUCTION}

The worldwide, substantial change and the demands for intelligent managements systems, in the infrastructure require more new ways of contracting methods for the asset management of pavement maintenance than ever. Over the last years, confluence of changes in the road network system has been an increased emphasis on the asset management environment to contract out pavement maintenance activities. These changes are due to new demands, expectations of users, new policies, regulations, more complex designs, improved maintenance techniques, changing views on organizations and the transition of responsibilities.

In addition, set of climate changes may have more significant impacts than anticipated in years on the pavements. There is uncertainty around the precise impact of climate change during the next several decades and it is hard to predict the effects accurately for between fifty and a hundred years ahead (MIE and MEAAI, 2011). Also the awareness of environmental issues is getting essential by governmental organizations. Moreover considerable effort is being devoted than in the past for the noise production on the pavements. The Netherlands is a densely populated country currently having over 16 million residents, more than 3300 kilometers of national highways and approximately eight million road vehicles (RWS, 2010). Rijkswaterstaat ( the executive agency of the ministry of infrastructure and environment in the Netherlands) have to fulfill the maintenance requirements of constantly increasing traffic loads on pavements and make them produce even less noise at the same time. Technologically as well as economically demanding maintenance of pavement activities also constitutes the challenge for contractors.

Increasingly innovative processes and technological advances lead to a rapid upswing in the field of pavement maintenance management. Trend in the last years under asset management framework, investment decisions process consider different strategies, decisions are made on a more objective bases. Within asset management there is a move from public domain to more private enterprise and private organizations have become increasingly important in the decision-making processes. As a result of privatization within highway agencies, there is an increased need for management of not only the decision making process for rehabilitation programming, but also a requirement to safeguard the investment of the shareholders (taxpayers) through timely and appropriate levels of maintenance (Falls and Haas, 2002).

The budget for public work changes significantly depending on economy policy or financial status, the budget for repair also changes (Kobayashi, K., Ejiri R. and Do M., 2008). Funding for pavements maintenance activities does not appear to kept pace with changing circumstances over the past several years. Therefore road agencies should try to allocate their budgets for pavement maintenance in an optimal way.

These changing circumstances induce complexity in the contracting methods of pavement maintenance activities. In result, increasing complexity and changes severely affects the asset management strategies of transportation agencies and reduces their 
ability to control the maintenance activities (Demirel, et al., 2012). Despite the fact that current contracting practices on pavement maintenance activities are not sufficient to deal with changes providing the improved level of services. In this case, the main question is how to make cost effective decisions and efficient outsourcing of pavement maintenance activities in asset management system.

Dynamic contracting mechanism (DCM) is a very strong tool to control and improve maintenance activities dynamically in order to keep them adequate in the constant changes (Demirel, et al., 2012). A suitable contracting mechanism can be mentioned to assist road agencies in finding optimum strategies for providing and managing pavement assets in a serviceable condition per time step. It can be also stated that dynamic contracting play a key role to deliver optimum strategic objectives, with the aim of achieving cost effective and efficient outsourcing mechanism in pavement maintenance management of road network. Regarding to optimum strategies, dynamic contracting can be related to adaptive delta management programme in Netherlands (MIE and MEAAI, 2011), that is about doing what is necessary, neither too much nor too little.

\section{PAVEMENT MANAGEMENT}

Cluster of assets (pavements, bridges, lighting, barriers, etc.) are the components of the infrastructure network system. Comprehensive asset management for road network considers various types of management systems such as pavement management, traffic management, bridge management etc. The pavement management process provides systematic and objective procedures for maintaining the inventory of pavement infrastructure, monitoring pavement performance, planning and budgeting of pavement preservation actions (ACRP, 2011). An effective pavement management system should support an overall asset management process and help managing agencies to show better accountability to asset owners (public) (Dewan, 2004).

During pavement maintenance process changes can cause gains and losses. Asset management and its supporting tool pavement management can only be efficient if the contracting method is adaptive to both gains and losses.

\section{BROAD ASSET MANAGEMENT}

The main change to the role of road management systems has lead to more business-oriented approach. In the context of developments, the term 'asset management' is increasingly being used to characterize a 'business-like approach' to road network management (Jani, 2007). Asset management is the systematic and coordinated activities and practices through which an organization optimally and sustainably manages its assets and asset systems, their associated performance, risks and expenditures over their life cycles for the purpose of achieving its organizational strategic plan (PAS55-1, 2008).

Asset management way of doing business allows decision makers to do 
necessary aspects. According to report ACRP 69, (2012), asset management is to;

- Make better investment decisions

- Align managers, decision makers, and workers to a common purpose to seek solutions and make decisions that result in the best economic, service level and risk exposure outcomes

- Improve flexibility to respond to changes in the regulatory and commercial environment.

\section{DYNAMIC APPROACH TO ASSET VALUE}

New technology affects the value of investments directly and indirectly because of the way it changes patterns of demands (Neufville, De R. and Scholtes, S., 2011). Approaches to the asset value in monetary terms such as Net Present Value or the Internal Rate of Return recognize the static view of value. Among this static view of problem, standard procedures generally do not cope with possible change of value in constantly changing demand and supply of maintenance methods. The living building concept as presented by De Ridder (2007) aims to involve all parties in the supply to deal adequately with changing technology, changing regulations, and changing demands throughout the entire life cycle of built objects. Here the variables value, price and cost are time dependent, in order for any chosen maintenance activity to achieve success. This enables the parties to regulate risks and take advantage of upside benefit. By creating more value against little more costs or little less value against substantial reduction of costs over the range of possible futures, these options lead to an increase on benefit and overall average returns. Within such an arrangement, the process can then be dynamically controlled, i.e. clients can alter their initial demand and calculate the impact on the initial price, and vice versa supplying parties are enabled to come up with new solutions that may reduce costs, or deliver additional value (De Ridder, H.A.J. and Vrijhoef, R., 2007). (Figure 1).

The need for maintenance activities requires dynamic contracting hence any change in asset value can simply be paid.

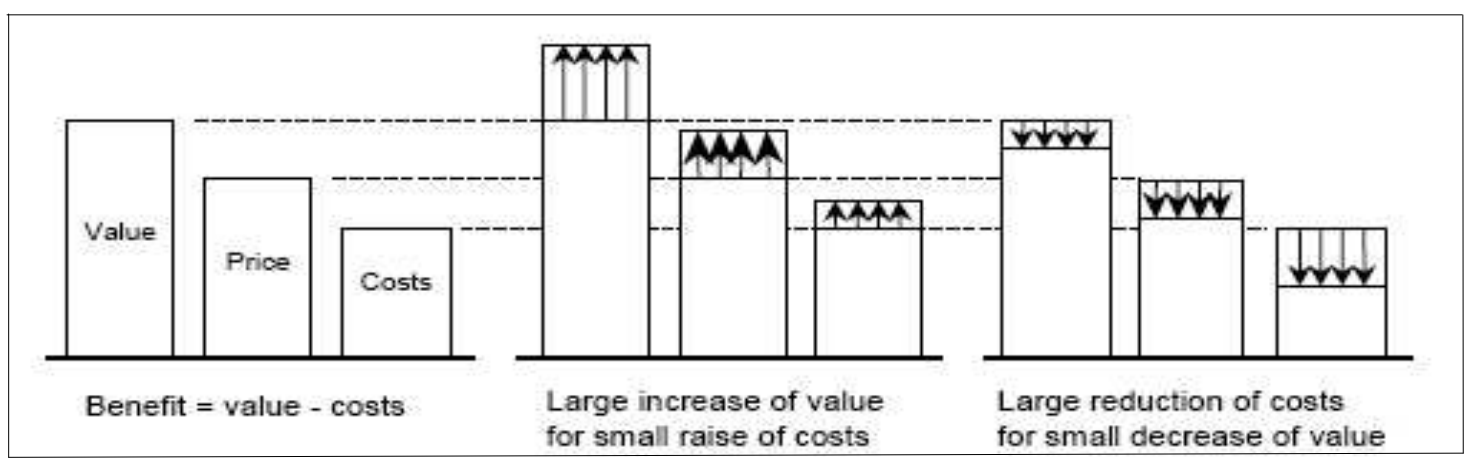

Figure 1: Value-Price-Cost Model (De Ridder, H.A.J. and Vrijhoef, R., 2007). 


\section{DYNAMIC CONTRACTING MECHANISM}

Dynamic contracting is a mechanism for structuring a maintenance problem, representing its elements and relations, and for relating those elements to overall goals of parties to deal with changing circumstances in time being.

Effective dynamic contracting mechanism should deal with changing circumstances during the life cycle of assets, support an overall asset management process and adapt decisions for doing what is necessary neither better nor little.

DCM as an evolving new idea of asset management system can be attractive for the attention of road agencies. As dynamic contracting is still evolving mechanism, road agencies need to organize their road network management plans clearly and provide convenient initiatives to the time being.

DCM is not based on any single contracting method; it is a comprehensive and relevant collection of optimal procedures for providing and managing of assets in a serviceable condition.

\section{DYNAMIC CONTRACTING MECHANISM IN RELATION WITH PAVEMENT MAINTENANCE MANAGEMENT}

In this changing world, faced with financial crisis, road agencies are looking for more efficient and effective way to manage pavement maintenance activities in such a way that supports broad asset management process. In this case, DCM can be a tool to control and manage the pavement maintenance activities dynamically between asset manager and contractors in broad asset management process. (Figure 2).

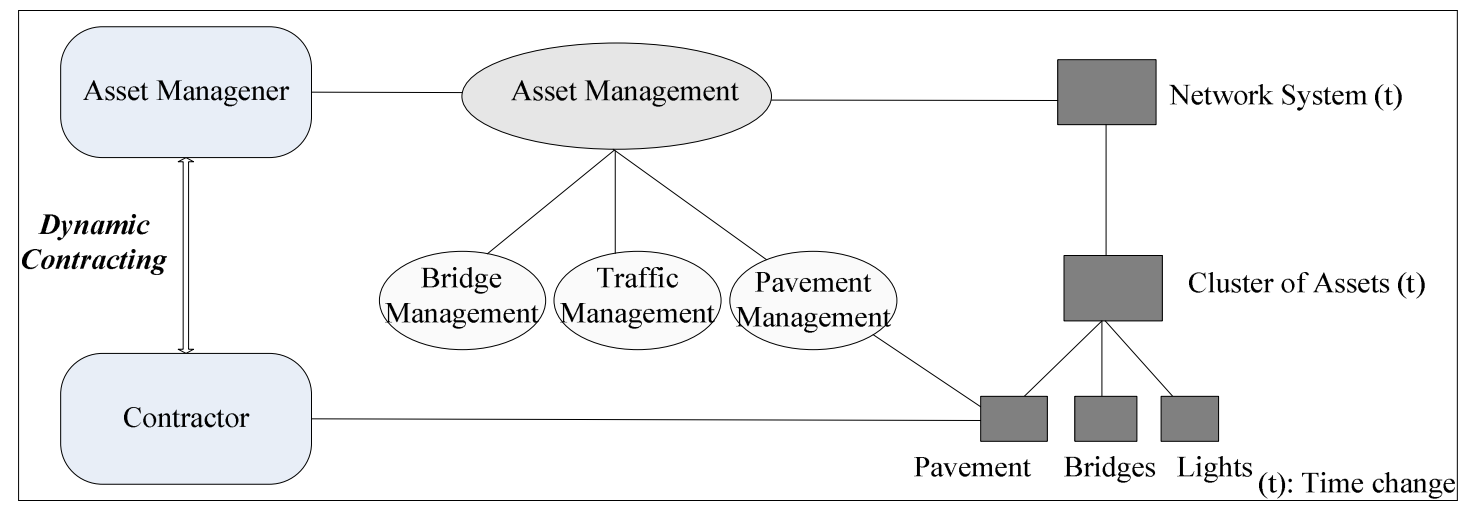

Figure 2: Dynamic contracting mechanism

In practice, with DCM, the information from pavement management and asset management can be used for investment decisions, planning of financial facilities, estimating amount of maintenance activities and asset valuation. DCM also enables to find optimum strategies for managing and preservation of pavements and assist parties valuation of these assets dynamically. Within this agreement supplying and demanding 
parties can deal with changing circumstances and incorporate with different flexible new solutions such as reducing costs or delivery of additional value. (Figure 3 )



Figure 3: Value, price and cost model integrated with dynamic contracting

DCM for pavement maintenance activities can make implementation and management more transparent. For the pavement maintenance operations contracting period can be decomposed into small periods. Road agencies and contractors enable to control maintenance activities and allocated budgets per time step for the coming periods, not like fix type of contracts. Phases of contracting periods provides decision makers to cope with changing circumstances derived through demands, climate etc., and reduce the impacts of these changes. It also increases the possible gains from the improvements of technology.

\section{DISCUSSION AND CONCLUSION}

Today, pavement maintenance activities require more efficiency, as the road network become more complex in the course of time due to constant changes. As a result, to manage road network and its assets becomes more critical than ever. Dynamic contracting mechanism concept represents a new approach to delivery of pavement maintenance activities. It brings out a discussion how an adaptive contracting mechanism can be introduced for optimal decision-making and efficient outsourcing in order to keep assets adequate. Despite the possibility of changing circumstances it offers advantages to demanding and supplying parties, based on dynamic valuation of assets. In addition, as a key factor adaptation to continuous changes, with focus on doing what is necessary neither too much nor too little for pavement maintenance activities. This keeps taking advantage of changes and avoids losses.

\section{REFERENCES}

ACRP, SYNETHESIS 22, (2011). "Common Airport Pavement Maintenance Practices." Transportation Research Board, Washington D.C.

ACRP, REPORT 69, (2012). "Asset and Infrastructure Management for AirportsPrimer and Guidebook”. Transportation Research Board, Washington D.C. 
De Ridder, H.A.J. and Vrijhoef, R. (2007). "Living Building Concept Applied to Healthcare Facilities." $4^{\text {th }}$ International research symposium SCRI, University of Salford, Salford, UK, 373-384

Demirel, H.C., De Ridder, H.A.J. and Hertogh, M. (2012). "Dynamic Contracting: An Asset Management Tool in Controlling Infrastructure Maintenance Activities." Unpublished paper.

Dewan, S. A. (2004). "Pavement management and Asset Management Side-by-Side." $6^{\text {th }}$ International Conference on Managing Pavements, Brisbane, Australia.

Falls, L.C. and Haas, R. (2002). "Asset Valuation Methodologies and Performance Measurement in Life-Cycle Analysis." Conference of the Canadian Society for Civil Engineering, Montréal, Québec, Canada.

Jani, S. (2007). "Road Asset Valuation and Management- Case Study Finland." International Seminar on Sustainable Road Financing and Investment, Arusha, Tanzania.

Kobayashi, K., Ejiri R. and Do M. (2008). "Pavement Management Accounting System.” Journal of Infrastructure Systems, ASCE, 14:159-168

Ministry of Infrastructure and the Environement (MIE) and Ministry of Economic Affairs, Agriculture and Innovation (MEAAI), (2011). "Delta Programme 2012, Working on the Delta." Den Haag, Netherlands.

Neufville, De R. and Scholtes, S. (2011). "Flexibility in Engineering Design." The MIT Press, Massachusetts Institute of Technology.

PAS55-1, (2008). "Asset Management, Part 1: Specification for the Optimized Management of Physical Assets." ISBN: 9780580509759. British Standards. London, UK.

Rijkswaterstaat (RWS), (2010). "Quite Roads: Set to music.” Den Haag, Netherlands.

Verlaan, J. and De Ridder, H.A.J. (2007). "IRAM: An Infrastructure Related Asset Management Model." $4^{\text {th }}$ International research symposium SCRI, University of Salford, Salford, UK, 79-93 